\title{
A model assessment of satellite observed trends in polar sea ice extents
}

\author{
Konstantin Y. Vinnikov, ${ }^{1}$ Donald J. Cavalieri, ${ }^{2}$ and Claire L. Parkinson ${ }^{2}$ \\ Received 21 November 2005; revised 23 January 2006; accepted 25 January 2006; published 3 March 2006.
}

[1] For more than three decades now, satellite passive microwave observations have been used to monitor polar sea ice. Here we utilize sea ice extent trends determined from satellite data for both the Northern and Southern Hemispheres for the period 1972(73)-2004, and assess and interpret them using results from simulations by eleven climate models. In the Northern Hemisphere (NH), observations show a statistically significant decrease of sea ice extent and an acceleration of sea ice retreat during the past three decades. However, from the modeled natural variability of sea ice extents in control simulations, we conclude that the acceleration is not statistically significant and should not be extrapolated into the future. Most of the models, like the observations, show an absence of a prominent seasonal cycle in the trend values. Both observations and model simulations show that climate variability in sea ice extent in the Southern Hemisphere (SH) is much larger than in the $\mathrm{NH}$ and that the $\mathrm{SH}$ sea ice extent trends are not statistically significant. Citation: Vinnikov, K. Y., D. J. Cavalieri, and C. L. Parkinson (2006), A model assessment of satellite observed trends in polar sea ice extents, Geophys. Res. Lett., 33, L05704, doi:10.1029/ 2005 GL025282.

\section{Introduction}

[2] In an earlier attempt to use climate models to assess and interpret the observed contemporary trend in Northern Hemisphere (NH) sea ice extents, Vinnikov et al. [1999] were limited by the brevity of the available satellite record, less than two decades, and by having simulations from only two climate models available at that time. Neither of those models was able to simulate realistically sea ice in the Southern Hemisphere (SH). Two new factors move us now to return to a model assessment of the observed climatic trends. The first factor is that Cavalieri et al. [2003] extended the Parkinson et al. [1999] records of sea ice extents back to 1972-1973 and forward to 2002. The second factor is that 20th century climate changes have recently been simulated using mostly the same external forcing by several climate modeling centers around the world for the Fourth Intergovernmental Panel on Climate Change (IPCC) Climate Change Assessment. The results of these simulations are available through the Program for Climate Model Diagnostics and Intercomparison (PCMDI) at Lawrence Livermore National Laboratory, USA.

\footnotetext{
${ }^{1}$ Department of Atmospheric and Oceanic Science, University of Maryland, College Park, Maryland, USA.

${ }^{2}$ Cryospheric Sciences Branch, NASA Goddard Space Flight Center, Greenbelt, Maryland, USA.
}

Copyright 2006 by the American Geophysical Union. 0094-8276/06/2005GL025282\$05.00
[3] The time series of satellite observed monthly sea ice extents for the north and south polar regions [Cavalieri et al., 2003] used in this analysis has been updated through 2004. Taking into account the known physics of microwave radiation, radiometer specifications, and sea ice retrieval algorithms, we estimate that an appropriate model correspondence with the observed ice extents, defined as the integrated area with ice concentration of at least $15 \%$, is the simulated area with ice thickness greater than $6 \mathrm{~cm}$ and ice concentration greater than or equal to $15 \%$. This criterion has been used for calculating simulated sea ice extents from climate model outputs, which include ice thickness and ice concentration as the two main sea ice outputs. To determine the simulated NH sea ice extents for 1972-2004 and the simulated SH sea ice extents for 1973-2004, for each of the selected models we used the "20th Century simulation (20C3M)" run1 and the first few years of the "Future climate simulations: scenario SRES A2" run1, which is a continuation of $20 \mathrm{C} 3 \mathrm{M}$ run1. Through 2004, the SRES A2 scenario does not differ from other forcing scenarios for future climate simulations. We also used the multi-centennial "Pre-Industrial control runs (PICTRL)" of the same models to assess natural climate variability in model simulated sea ice extents. The sea ice simulation data came from the following eleven climate models: (1) UKMO-HadCM3 [Gordon et al., 2000] and (2) UKMO-HadGEM1 [Johns et al., 2005], both from the United Kingdom Met Office Hadley Centre; (3) ECHAM5/MPI-OM [Marsland et al., 2003], from the Max Planck Institute for Meteorology, Hamburg, Germany; (4) CGCM3.1 (T-47) [Kim et al., 2002], from the Canadian Centre for Climate Modeling and Analysis;

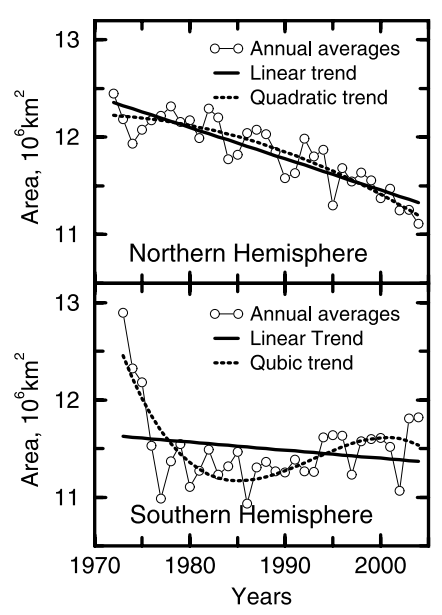

Figure 1. Satellite observed annual mean sea ice extents in the Northern and Southern Hemispheres and polynomial approximations of climatic trends. 
(5) CSIRO-Mk3.0 [Gordon et al., 2002], from the Commonwealth Scientific and Industrial Research Organization, Australia; (6) MIROC3.2 (medres) [Hasumi and Emori, 2004], Model for Interdisciplinary Research on Climate, Japan; (7) BCCR-BCM2.0 [Furevik et al., 2003], from the Bjerknes Centre for Climate Research, Norway; (8) GISS-ER [Schmidt et al., 2005], from the NASA Goddard Institute for Space Studies, USA; (9) IPSL-CM4 [Marti et al., 2005], from the Institute Pierre Simon Laplace, France; (10) INM-CM3.0 [Diansky and Volodin, 2002], from the Institute of Numerical Mathematics, Russian Academy of Science, Russia; (11) GFDL-CM2.1 [Griffies et al., 2005], from the NOAA Geophysical Fluid Dynamics Laboratory, USA. C. L. Parkinson et al. (Evaluation of the simulation of annual cycle of Arctic and Antarctic sea ice coverages by eleven major global climate models, submitted to Journal of Geophysical Research, 2006), using the same satellite observed data for 1979-2004 have shown that the majority of these models realistically simulate at least key aspects of the seasonal cycle and geographical patterns of sea ice in both hemispheres.

\section{Trends in Observed and Model Simulated Sea Ice Extents}

[4] Satellite observed annual mean sea ice extents in the Northern and Southern Hemispheres are shown in Figure 1. Cavalieri et al. [1997] reported hemispheric asymmetry in global sea ice changes during 1978-1996 including opposing trend lines. With the extended record, the two hemispheres continue to behave differently, but it is no longer the case that the sign of the trend in the two cases differs. Sea ice in the NH continues, with the extended record, to have a negative trend, with a mean rate of -0.32 . $10^{6} \mathrm{~km}^{2} / 10 \mathrm{yr}$, and there is an acceleration, of approximately $-0.16 \cdot 10^{6} \mathrm{~km}^{2} /(10 \mathrm{yr})^{2}$ in the rate of ice retreat. Sea ice in the $\mathrm{SH}$ no longer has a positive trend, once the data from the early and mid-1970s are included. The best approximation for the SH required a 3rd degree polynomial, and even then the coefficients are not statistically significant. A linear least squares fit line for the SH ice for 1973-2004 has a negative sign as in NH but it is much smaller in magnitude and is not statistically significant. The multi-year averages, standard deviations, trends and standard errors of trends in the observed data and in model simulated results are given in Table 1 and will be discussed in the next section.

[5] The seasonal cycles of linear trends by month for 33 years of satellite microwave observations, 1972-2004, in the NH (thick lines) and for 32 years, 1973-2004, in the SH (thin lines) are shown in Figure 2. Vertical bars display standard errors of the trend estimates. The observed sea ice extents do not differ noticeably compared to earlier published estimates for a shorter period [Cavalieri et al., 2003]. The corresponding seasonal cycles of trends in the model simulated sea ice extents for the same time intervals are also shown in Figure 2.

\section{Model Assessment of Observed Trends}

[6] The statistical approach used here to assess and interpret climatic trends observed at a limited time interval using long climate model control simulations have 

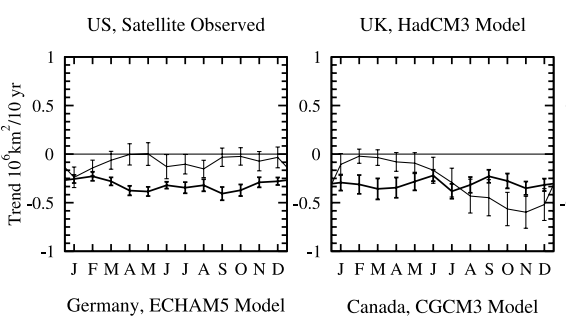

UK, HadGEM1 Model

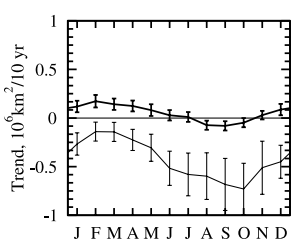

Canada, CGCM3 Model

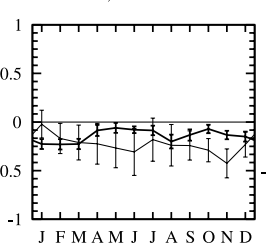

Japan, MIROC3 Model
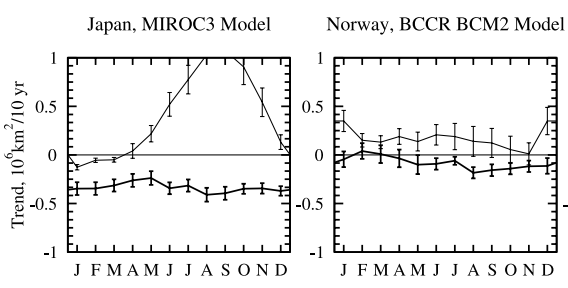

France, IPSL CM4 Model
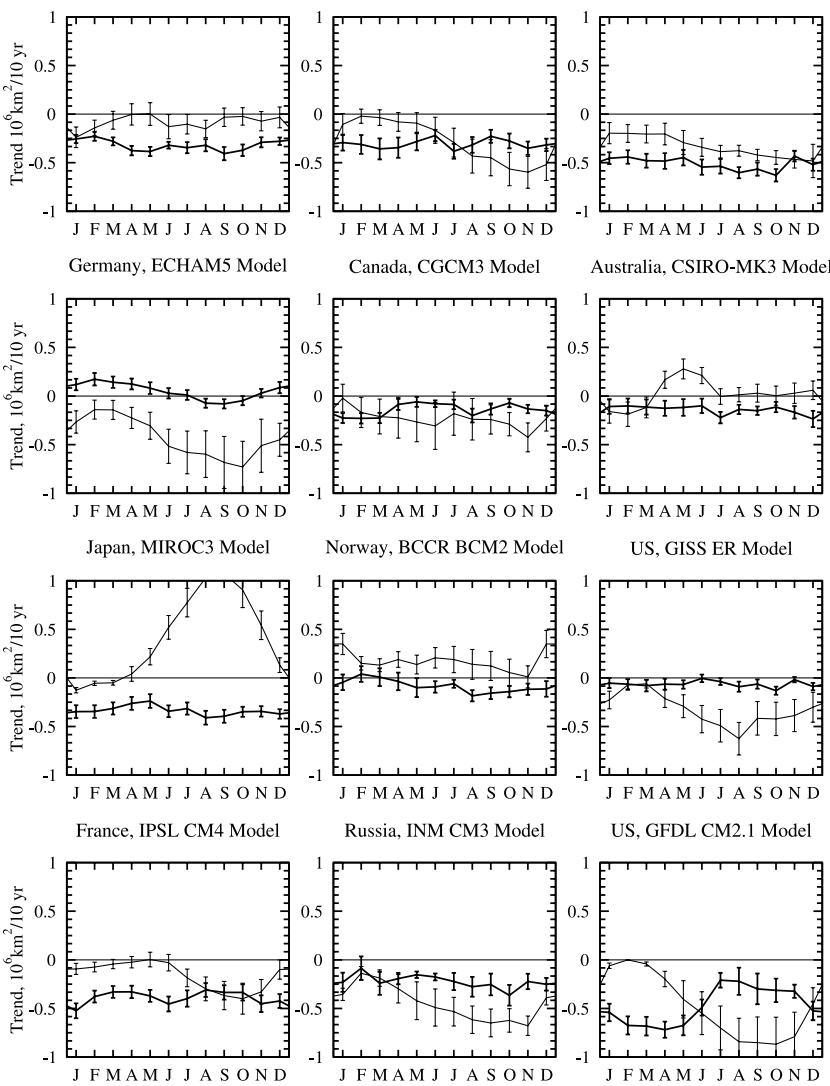

Australia, CSIRO-MK3 Mode

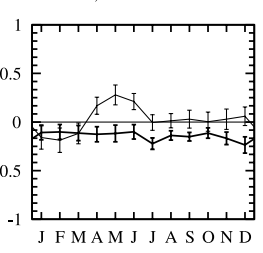

US, GISS ER Model

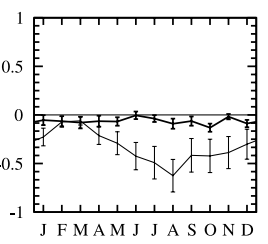

US, GFDL CM2.1 Model

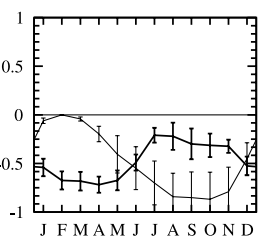

Figure 2. Seasonal cycle of observed and model simulated 1972(73)-2004 trends in Northern (thick lines) and Southern Hemisphere (thin lines) sea ice extents. Vertical bars show standard errors of trend estimates.

been developed and tested earlier by Stouffer et al. [1994] and Vinnikov et al. [1999]. This approach estimates the frequency of occurrence of trends that exceed the observed one in a model simulated time series and provides a probability based on the assumption that the expected value of a trend is close to zero and that the sampling variability has a normal statistical distribution. If the observed trend exceeds twice its standard error then it is considered here to be statistically significant. The parameters given in Table 1 can be used with other thresholds of statistical significance. Table 1 also gives the length of available multi-centennial control simulations for each of the models $(\boldsymbol{N})$ and the percent occurrences of trends $(\boldsymbol{P})$ that exceed the observed trends in moving windows of length $32-33$ years through the multi-centennial runs.

[7] Comparing the climate model simulations with the observations:

[8] (1) Satellite observed annual mean multi-year averages for 33-32 years of sea ice extents $(\boldsymbol{\alpha})$ are almost equal in both hemispheres $\left(11-12 \cdot 10^{6} \mathrm{~km}^{2}\right)$. About half of the models agree that the annual average sea ice extents in the two hemispheres do not differ much for the present-day climate. We cannot talk about statistical significance of this difference, because models continue to drift over their internal equilibrium states. The hemispheric results for the other half of the models differ considerably.

[9] (2) The observed standard deviation of detrended annual mean sea ice extents $(\boldsymbol{\sigma})$ in the $\mathrm{NH}(0.16$. $\left.10^{6} \mathrm{~km}^{2}\right)$ is much smaller than in the SH $\left(0.38 \cdot 10^{6} \mathrm{~km}^{2}\right)$. All the models agree with the larger interannual variability of sea ice extents in the $\mathrm{SH}$ versus $\mathrm{NH}$, but the observed variability is near the low end of the model simulated variability in both hemispheres. More representative estimates of modeled natural variability of sea ice extents $\langle\boldsymbol{\sigma}\rangle$ were obtained from multi-centennial control simulations of the preindustrial climate than for the 33/32-year observation period by averaging variances of detrended ice extents computed in the 32-33-year moving windows. The results from some of the models suggest that the years of observation, 1972-2004, may represent a period of relatively low interannual variability of sea ice extents in the NH. However, it is possible that all of the models except two (GISS-ER and CGCM3) overestimate natural variability of NH sea ice extents.

[10] (3) The observed decreasing trend in $\mathrm{NH}$ sea ice extents, $\beta \approx-0.3 \cdot 10^{6} \mathrm{~km}^{2} / 10 \mathrm{yr}$, is statistically significant based on the error statistics $\sigma_{\beta}$ and $\sigma_{\langle\beta\rangle}$ for sea ice extents from most of the models. Six of the models have zero occurrences of trend that exceeds the observed trend in control runs. The largest percent occurrence is $4 \%$, a small value that does not change the overall conclusion. The observed sea ice retreat in the $\mathrm{SH}$ is much weaker and statistically not significant, but the sign of the trend is reproduced in simulations of 8 of the 11 climate models. The occurrence of a trend that exceeds the observed trend in control simulations of the different models varies from $15 \%$ to $46 \%$, suggesting that natural climate variability often generates trends at least as large as the observed trend in the $\mathrm{SH}$.

[11] (4) Acceleration in the rate of sea ice retreat observed in the NH is statistically significant according to calculations based on the observed data by themselves. Several of the models also obtain a statistically significant acceleration for the 1972-2004 period, although only one, GISS-ER, obtains a statistically significant acceleration from the multicentennial run. Further, the GISS model obtains an acceleration that is approximately twice as large as in the observed data. Clearly, acceleration is necessary at some point in order to transition from a stationary sea ice regime, as seems to have existed in the $\mathrm{NH}$ ice cover in the first half of the 20th century [Vinnikov et al., 1999], to the current rate of retreating sea ice cover.

[12] (5) As can be seen in Figure 2, the trends of sea ice retreat in the NH do not vary significantly among the months, with no strong seasonal dependence. The $1973-$ 2004 trends in the SH are also negative, but are much smaller in magnitude than the trends in the $\mathrm{NH}$ and are insignificant for each month. The modeled $\mathrm{NH}$ trend is larger than the observed trend in some models, smaller than the observed trend in other models, but only one of the models does not reproduce a $1972-2004 \mathrm{NH}$ sea ice retreat. Most of the models, like the observations, show an absence of a prominent seasonal cycle in the trend values.

\section{Concluding Remarks}

[13] We have attempted to place more than three decades of satellite observed polar sea ice variations into a broader statistical context by comparing them with sea ice simula- 
tions from eleven state-of-the-art climate models. The simulations were used both for the time period of satellite observations (1972/73-2004) and for multi-centennial control runs of pre-industrial climate. Our results are based on only a single model simulation for each of the models, i.e., one sample from a variety of possible realizations that can be obtained using each model. Only the main components of external forcing in these model simulations are the same. On the other hand, the minor components of external forcing are not sufficiently different to explain the differences of statistics obtained from the models. Initial states of the climate system are quite different as are the sensitivities of each model. As a result, the models demonstrate a wide range of variations in simulated sea ice extents. Nevertheless, the climate model simulations provide statistical support to the conclusion that the satellite observed retreat in NH sea ice extents is a real climate change and that the retreat is a response to changes in the observed external forcing of the global climate system. An absence in the NH of a significant seasonal dependence of monthly trends, the acceleration of sea ice retreat, and the lack of a statistically significant trend observed in SH sea ice extent all deserve further investigation.

[14] Acknowledgments. We thank the eleven modeling groups and the PCMDI Program for making the results of the sea ice simulations available, and the reviewers for their valuable comments. KYV was supported by NASA grants NAG510746 and NNG04GN15G. DJC and CLP were supported by NASA's Cryospheric Sciences Program. The authors contributed equally to this work.

\section{References}

Cavalieri, D. J., P. Gloersen, C. L. Parkinson, J. C. Comiso, and H. J. Zwally (1997), Observed hemispheric asymmetry in global sea ice changes, Science, 272, 1104-1106.

Cavalieri, D. J., C. L. Parkinson, and K. Y. Vinnikov (2003), 30-year satellite record reveals contrasting Arctic and Antarctic decadal sea ice variability, Geophys. Res. Lett., 30(18), 1970, doi:10.1029/ 2003GL018031.
Diansky, N. A., and E. M. Volodin (2002), Simulation of present-day climate with a coupled atmosphere-ocean general circulation model, Izv. Atmos. Oceanic Phys., 38(6), 732-747.

Furevik, T., et al. (2003), Description and evaluation of the Bergen climate model: ARPEGE coupled with MICOM, Clim. Dyn., 21, 27-51.

Gordon, C., C. Cooper, C. A. Senior, H. Banks, J. M. Gregory, T. C. Johns, J. F. B. Mitchell, and R. A. Wood (2000), The simulation of SST, sea ice extents and ocean heat transports in a version of the Hadley Centre coupled model without flux adjustments, Clim. Dyn., 16, 147-168.

Gordon, H. B., et al. (2002), The CSIRO Mk3 Climate System Model, Atmos. Res. Tech. Pap. 60, 130 pp., Commonw. Sci. and Res. Organ., Aspendale, Victoria, Australia.

Griffies, S. M., et al. (2005), Formulation of an ocean model for global climate simulations, Ocean Sci., 1, 45-79.

Hasumi, H., and S. Emori (Eds.) (2004), K-1 coupled GCM (MIROC) description, K-1 Tech. Rep. 1, 34 pp., Cent. for Clim. Syst. Res., Univ. of Tokyo, Tokyo.

Johns, T., et al. (2005), HadGEM1-Model description and analysis of preliminary experiments for the IPCC Fourth Assessment Report, Tech. Note 55, 74 pp., Hadley Cent., Exeter, U. K.

Kim, S.-J., G. M. Flato, G. J. Boer, and N. A. McFarlane (2002), A coupled climate model simulation of the Last Glacial Maximum, part 1: Transient multi-decadal response, Clim. Dyn., 19, 515-537.

Marsland, S. J., H. Haak, J. H. Junqclaus, M. Latif, and F. Roske (2003), The Max-Plank-Institute global ocean/sea ice model with orthogonal curvilinear coordinates, Ocean Modell., 5, 91-127.

Marti, O., et al. (2005), The new IPSL climate system model: IPSL-CM4, 86 pp., Inst. Pierre Simon Laplace des Sci. de l'Environ. Global, Paris. Parkinson, C. L., D. J. Cavalieri, P. Gloersen, H. J. Zwally, and J. C. Comiso (1999), Arctic sea ice extents, areas, and trends, 1978-1996, J. Geophys. Res., 104(C9), 20,837-20,856.

Schmidt, G. A., et al. (2005), Present day atmospheric simulations using GISS ModelE: Comparison to in-situ, satellite and reanalysis data, J. Clim., 19, 153-192.

Stouffer, R. J., S. Manabe, and K. Y. Vinnikov (1994), Model assessment of the role of natural variability, Nature, 367, 634-636.

Vinnikov, K. Y., A. Robock, R. J. Stouffer, J. E. Walsh, C. L. Parkinson, D. J. Cavalieri, J. F. B. Mitchell, D. Garrett, and V. F. Zakharov (1999), Global warming and Northern Hemisphere sea ice extent, Science, 286, $1934-1937$.

D. J. Cavalieri and C. L. Parkinson, Cryospheric Sciences Branch, NASA Goddard Space Flight Center, Greenbelt, MD 20771, USA.

K. Y. Vinnikov, Department of Atmospheric and Oceanic Science, University of Maryland, College Park, MD 20742, USA. (kostya@atmos. umd.edu) 